\title{
Dissociation of spontaneous testicular recrudescence and photorefractoriness in the Syrian hamster
}

\author{
R. S. Donham, G. Goodear and M. H. Stetson \\ Department of Biological Sciences, University of Delaware, Newark, DE 19716, USA
}

\begin{abstract}
In male Syrian hamsters, short days induce regression of the reproductive system, but eventually spontaneous recrudescence occurs ensuing from refractoriness to the inhibitory photoperiod. Although the photoperiod of $12 \mathrm{~L}: 12 \mathrm{D}$ (12 h light:12 h dark) may act like a short day by inducing the testicular cycle outlined above, it may fail to evoke the increase of circulating concentrations of prolactin that accompanies testicular recrudescence. This photoperiod may fail to induce photorefractoriness, as indicated by the prolonged low concentrations of prolactin in the blood. Herein, hamsters were exposed to either $8 \mathrm{~L}: 16 \mathrm{D}$ or $12 \mathrm{~L}: 12 \mathrm{D}$ from weaning and by 28 weeks exposure to either photoperiod, the hamsters had large testes (following recrudescence from a photoperiod induced-regression). Transfer to $8 \mathrm{~L}: 16 \mathrm{D}$ from $12 \mathrm{~L}: 12 \mathrm{D}$ at 28 weeks resulted in a second testicular regression and recrudescence. In a second experiment, the testes of hamsters moved to $8 \mathrm{~L}: 16 \mathrm{D}$ from $12 \mathrm{~L}: 12 \mathrm{D}$ after 29 weeks exposure to the latter photoperiod similarly regressed and then regrew. Serum concentrations of prolactin decreased in these males after transfer to the shorter daylength but also decreased in hamsters kept under 12 L:12 D; both groups were usually below those of hamsters moved to $14 \mathrm{~L}: 10 \mathrm{D}$. These results show that exposure for 28 or 29 weeks to $12 \mathrm{~L}: 12 \mathrm{D}$ was insufficient to induce photorefractoriness, despite the recrudescence of the testes following involution.
\end{abstract}

\section{Introduction}

Reduction of photoperiod results in a decrease in basal concentrations of circulating prolactin in many, if not all, photoperiodic mammals. In Syrian hamsters, following transfer to a short day, concentrations of prolactin decrease with approximately the same delay as do LH and FSH concentrations (Goldman et al., 1981; Steger and Bartke, 1991). However, prolonged exposure results in a spontaneous reversal of the suppressive effects of short days; again, the recrudescence of the reproductive axis is accompanied by an increase in the concentrations of prolactin (Matt and Stetson, 1980; Goldman et al., 1981). This spontaneous development of photorefractoriness remains one of the major dilemmas of photoperiodism. The significance of photorefractoriness for hamsters is that it results in the induction of reproductive activity well before the daylengths of winter are long enough to stimulate the reproductive system (Reiter, 1981; Watson-Whitmyre and Stetson, 1988).

How photoperiod regulates prolactin secretion is only partly understood. Since pinealectomy blocks the suppressive effect of short days (Blask et al., 1986; Vriend and Wasserman, 1986) and administration of melatonin mimics the effects (Little et al., 1986; Steger and Gay-Primel, 1990), the interpretation of daylength is almost certainly dependent on the translation

Revised manuscript received 31 May 1996 of photoperiodic information via the pineal gland output of melatonin. Melatonin secretion by the pineal gland is rhythmic and release is restricted to the dark phase (Rollag et al., 1980; Reiter, 1981, 1991).

Although the effects of short days are similarly translated as inhibition of LH, FSH and prolactin secretion through the mediation of melatonin, the secretion of gonadotrophins may be separated experimentally from that of prolactin. For example, reproductive maturation occurs at the same rate in young golden hamsters whether they are raised under a photoperiod of long days or of short days or even if they are blinded (Gaston and Menaker, 1967; Darrow et al,, 1980; Donham et al., 1994). However, concentrations of prolactin are depressed by short days as early as 21 days of age (Donham et al., 1994). Furthermore, recrudescence of the testes following prolonged exposure to $12 \mathrm{~L}: 12 \mathrm{D}$ occurs unaccompanied by an increase in plasma concentrations of prolactin (Donham et al., 1994). Since the concentrations of prolactin remained depressed in the latter experiments, it is probable that the apparently unique photoperiod of 12 L:12 D may fail to engage the mechanism that results in the development of photorefractoriness.

The purpose of the experiments reported herein is to determine whether the testicular recrudescence that occurs under this intermediate photoperiod results from photorefractoriness. 


\section{Materials and Methods}

Male Syrian hamsters (Mesocricetus auratus) from the colony at the University of Delaware were exposed to a light cycle of I4 L:10 D (lights on from 06:00 to 20:00 h; light intensity of 400-800 lux) until transfer to the experimental photoperiods. Animals were housed five to seven per cage and provided with food and water ad libitum. Individuals were identified by variations in pelage colour, pattern and length.

\section{Experiment 1}

At weaning ( 3 weeks of age), males were transferred to photoperiods of either 8 L:16 D (lights on 12:00 to 20:00 h) or $12 \mathrm{~L}: 12 \mathrm{D}$ (lights on 08:00 to 20:00 h). They remained under these photoperiods for 28 weeks when each group was subdivided and a third of each was transferred to the opposite photoperiod. Fourteen weeks later ( 42 weeks after the first transfer), half of the hamsters on 12 L:12 D were transferred to 8 L:16 D. This transfer included animals that had been on the longer photoperiod solely until that time and also hamsters that had been on 8 L:16 D during the first 28 weeks, and then exposed to $12 \mathrm{~L}: 12 \mathrm{D}$ for 14 weeks.

At intervals during the experiment, the testicular volume was measured by determination of the length and width of one testis through the scrotum with calipers under light ketamine and pentobarbital anaesthesia. Paired testicular volume was calculated from this measurement using the formula for a prolate spheroid (Watson-Whitmyre and Stetson, 1985):

$$
\mathrm{Vol}=8 / 3(L / 2)(W / 2)^{2}, L: \text { length; } W: \text { width }
$$

assuming similar volumes for each testis of a pair. This method allows for repeated measurements with no scar tissue formation or adhesion of the testis and the tunica. Full spermatogenesis is limited to paired testes volumes of $2000 \mathrm{~mm}^{3}$ or above (Gaston and Menaker, 1967).

\section{Experiment 2}

Prepubertal male hamsters were transferred to $12 \mathrm{~L}: 12 \mathrm{D}$ at weaning ( 3 weeks of age). At 19 weeks of age, when Rollag et al. (1982) report that testis size is minimal in hamsters held from weaning under a photoperiod of 10 L:14 D, hamsters with obviously developed testes were excluded. At 21, 25 and 29 weeks of age, blood samples were collected by cardiac puncture without anaesthesia and testicular dimensions obtained as described for Expt 1. At 29 weeks the group was subdivided and a third transferred to $14 \mathrm{~L}: 10 \mathrm{D}$ and a third to $8 \mathrm{~L}: 16 \mathrm{D}$ with the remainder left under 12 L:12 D (8-9 animals per group). Subsequently blood samples were collected at intervals of 2 weeks and the testis size was measured more infrequently. The experiment was terminated when the animals were 53 weeks old and the testes were then measured in the same way and the trunk blood was collected.

\section{Analyses}

The blood was allowed to clot overnight at $4{ }^{\circ} \mathrm{C}$ and the serum collected after centrifugation at $1500 \mathrm{~g}$ for $30 \mathrm{~min}$. The samples were frozen at $-20^{\circ} \mathrm{C}$ until they were assayed for prolactin. All samples from a single experiment were assayed together. Prolactin concentration was measured using materials provided by A. F. Parlow (Pituitary Hormones and Antisera Center, Torrance, CA). Both the antigen for iodination (with chloramine T: Sigma Chemical Co., St Louis, MO) and the reference preparation were hamster prolactin (AFP10302E); the antiserum was AFP-2821591. Assay sensitivity was $1.5 \mathrm{ng} \mathrm{ml}^{-1}$ and the intra-assay coefficient of variation was $10 \%$.

General linear models ANOVA and repeated measures ANOVA were used to determine the significance of differences between means (SAS Ver 6.07, SAS Institute Inc., Cary, NC). Means comparisons were made using the predicted difference (PDIFF) option of least-squares means. The hormone data were analysed after logarithmic transformation to enhance homogeneity of sample variance (Sokal and Rohlf, 1981). The hormone data are plotted as back-transformed means and standard error from the ANOVA.

\section{Results}

\section{Experiment 1}

There was an effect of both photoperiod and time on the size of the testes (Fig. 1; $\operatorname{Pr}>F<0.0001$ for both) and the interaction was also significant $(P<0.0001)$. After transfer of the hamsters to the opposite photoperiod at 28 weeks, only those moved from 12 L:12 D to $8 \mathrm{~L}: 16 \mathrm{D}$ subsequently had a significant change in testis size; testicular regression ensued and there was a second spontaneous recrudescence between 42 and 50 weeks of treatment, i.e., after 14 weeks exposure to 8 L:16 D (Fig. Ib).

The cohort of animals exposed to 12 L:12 D from 3 to 42 weeks and then transferred to $8 \mathrm{~L}: 16 \mathrm{D}$ (Fig. 1c) had a larger mean testicular volume at 13 weeks of exposure and did not vary significantly during the course of the experiment. In addition, the testes of animals initially exposed to $8 \mathrm{~L}: 16 \mathrm{D}$ that received 14 weeks of $12 \mathrm{~L}: 12 \mathrm{D}$ treatment (i.e., from 28 to 42 weeks of the experiment) failed to respond to the return to $8 \mathrm{~L}: 16 \mathrm{D}$ between 42 and 50 weeks (Fig. Ic).

\section{Experiment 2}

Both photoperiod and time significantly affected the paired testicular volume (Fig. 2a; $\operatorname{Pr}>F<0.0001$ for both) and the interaction of the time and photoperiod was significant $(P<0.0001)$. Before transfer to the experimental photoperiods from 12 L:12 D (29 weeks of age), the testicular volume increased (Fig. 2a), reaching a mean value of $4400 \mathrm{~mm}^{3}$ ( $P<0.0001$ versus mean testicular volume 8 weeks earlier). Subsequently, only the size of the testes of the $8 \mathrm{~L}: 16 \mathrm{D}$ group changed significantly: at 14, 16 and 20 weeks after transfer the mean testicular volume was significantly smaller than at the time of transfer $(P<0.0001$ in all cases). The mean testicular volume of the $8 \mathrm{~L}: 16 \mathrm{D}$ group was significantly smaller than that of the $12 \mathrm{~L}: 12 \mathrm{D}$ and the $14 \mathrm{~L}: 10 \mathrm{D}$ groups at 14 weeks $(P<0.0001$ in each case $)$. Testis size was not measured at 16 and 20 weeks for the last mentioned groups. Mean testicular volume of the $8 \mathrm{~L}: 16 \mathrm{D}$ group had returned to a value that was 

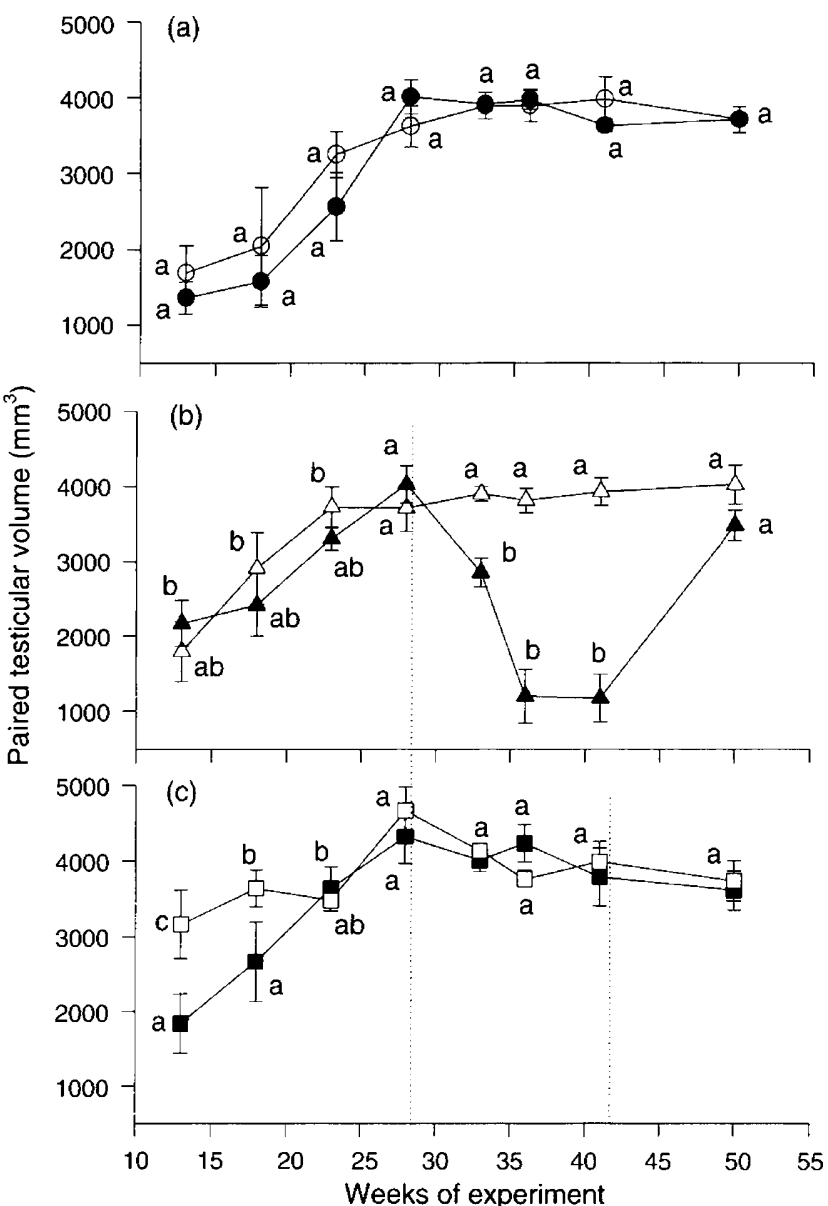

Fig. 1. Calculated paired testis volumes of hamsters in Expt 1. Sample sizes were: $(0) 8 \mathrm{~h}$ light:16 h dark only $15 ;(0) 12 \mathrm{~h}$ light:12 h dark

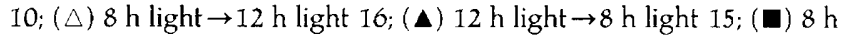
light $\rightarrow 12$ h light $\rightarrow 8 \mathrm{~h}$ light 8 ; ( $\square) 12 \mathrm{~h}$ light $\rightarrow 12 \mathrm{~h}$ light $\rightarrow 8 \mathrm{~h}$ light 8. Vertical dotted lines indicate when the transfers between photocycles occurred. Symbols and vertical lines are means \pm SFM. Letters refer to comparisons between groups at the same time; means with different letters are significantly different $(P<0.05)$.

not different from the other groups by 24 weeks after transfer (Fig. 2a).

There was an effect of both time $(\operatorname{Pr}>F<0.0001)$ and photoperiod $(\operatorname{Pr}>F<0.001)$ on prolactin and the interaction was significant $(\operatorname{Pr}>F<0.0007)$. Specifically, the concentrations increased before transfer at 29 weeks of treatment (Fig. $2 \mathrm{~b},-8$ versus 0 weeks; $P<0.0001$ ) and then, following the shift in photoperiods, prolactin concentration decreased and remained low for at least 20 weeks in the $8 \mathrm{~L}: 16 \mathrm{D}$ and the $12 \mathrm{~L}: 12 \mathrm{D}$ groups $(P<0.0001$ for all comparisons between 6 and 20 weeks after transfer and 0 weeks). In contrast, although the concentrations of prolactin in the $14 \mathrm{~L}: 10 \mathrm{D}$ group were often significantly lower after transfer $(6,8,16,20,22$, and 24 weeks versus 0 weeks $P<0.05$ in all comparisons), the concentrations of prolactin were also often greater than those in the $8 \mathrm{~L}: 16 \mathrm{D}$ and, especially, the $12 \mathrm{~L}: 12 \mathrm{D}$ groups (at 10, 12 and 18 weeks, $14 \mathrm{~L}: 10 \mathrm{D}$ versus either $12 \mathrm{~L}: 12 \mathrm{D}$ or $8 \mathrm{~L}: 16 \mathrm{D}$, $P<0.05$ in all comparisons). Between 20 and 24 weeks after transfer the concentrations of prolactin in the $12 \mathrm{~L}: 12 \mathrm{D}$ hamsters rebounded $(P<0.000320$ versus 22 or 24 weeks).
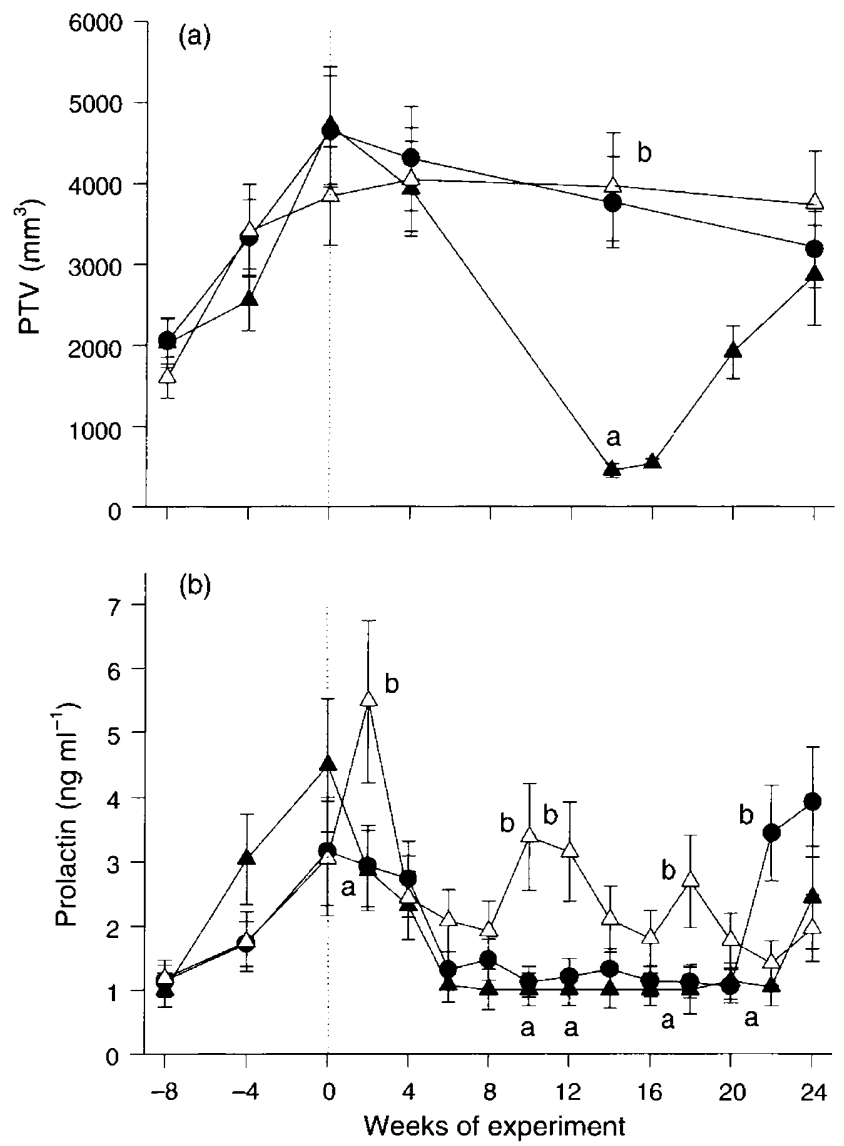

Fig. 2. Calculated (a) paired testis volumes (PTV) and (b) concentration of prolactin of hamsters in Expt 2. After exposure for 29 weeks ( 0 weeks on the horizontal axis) to $12 \mathrm{~h}$ light: $12 \mathrm{~h}$ dark, hamsters were moved to $14 \mathrm{~h}$ light: $10 \mathrm{~h}$ dark or $8 \mathrm{~h}$ light:16 h dark or remained under the original photoperiod. (-) $12 \mathrm{~h}$ light: $12 \mathrm{~h}$ dark; (A) $12 \mathrm{~h}$ light $\rightarrow 8 \mathrm{~h}$ light; (A) $12 \mathrm{~h}$ light $\rightarrow 14 \mathrm{~h}$ light. Values are means \pm SEM. Means with different letters are significantly different $(P<0.05)$.

\section{Discussion}

The results of Expts 1 and 2 suggest that treatment for 28 or 29 weeks at 12 L:12 D was insufficient to induce absolute photorefractoriness since the testes of these animals regressed when they were moved to a 8 L:16 D photoperiod. Insofar as we are aware, this is the first report that transfer to a 'short' photoperiod following spontaneous testicular recrudescence may induce a second testicular regression in Syrian hamsters. Since the hamsters were no longer responsive to the previously inhibitory photoperiod of $12 \mathrm{~L}: 12 \mathrm{D}$, they may be considered refractory to that photoperiod, but, unlike photorefractoriness induced by other (i.e. shorter) photoperiods, they still retain the ability to respond to a yet shorter day. Hastings et al. (1989) reported that photoperiodic history affected the response of LH to $12 \mathrm{~L}: 12 \mathrm{D}$ but that exposure to longer or shorter daylengths made little difference to the concentrations of prolactin. Malpaux $e t$ al. (1988) have reported a somewhat similar phenomenon in the development of refractoriness to short days in ewes since the season may be temporarily prolonged by exposure to a shorter daylength. 
Japanese quail develop a 'relative refractoriness' in that they become insensitive to a previously stimulatory photoperiod while retaining sensitivity to a longer daylength (Robinson and Follett, 1982; Nicholls et al, 1988; Follett and Pearce-Kelly, 1990). Wingfield (1993) also reported that song sparrows (Melospiza melodia) develop an insensitivity to a daylength that was previously stimulatory to reproduction. In birds, in general, development of refractoriness is to a photoperiod that previously stimulated reproductive activity and so is not quite analogous to the situation in hamsters which become refractory to the inhibitory photoperiods. However, our results suggest that phororefractoriness to the apparently unique $12 \mathrm{~L}: 12 \mathrm{D}$ photoperiod may be similar to that in birds and sheep in that the hamster is refractory to that particular photoperiod whilst retaining sensitivity to a more extreme daylength.

Although the complete progress of testicular activity from the time of weaning (week 0) was not observed, the data available from about 13 weeks exposure and from other reports (Reiter et al., 1970; Darrow et al., 1980; Rollag et al., 1982) allow the presumption that after a normal testicular development through about 10 weeks of age ( 7 weeks of exposure), the testes collapsed as a result of the inhibitory photoperiod. Recrudescence was initiated thereafter, so that by 28 weeks (Expt 1) or 29 weeks (Expt 2), significant reproductive recrudescence had occurred.

In Expt 1, at 13 weeks, some of the animals exposed for $12 \mathrm{~L}: 12 \mathrm{D}$ had larger testes than did animals held on $8 \mathrm{~L}: 16 \mathrm{D}$. These animals when challenged with $8 \mathrm{~L}: 16 \mathrm{D}$ after 42 weeks of $12 \mathrm{~L}: 12 \mathrm{D}$ also failed to respond to the shorter photoperiod. We suggest that these individuals did not respond to the original exposure to $12 \mathrm{~L}: 12 \mathrm{D}$ for the same reason that they did not respond to the second, shorter photoperiod, that they were non-photoresponsive to any inhibitory photoperiod. In other experiments, we have occasionally observed (R. S. Donham, P. Patel and M. H. Stetson, unpublished observations) variability in the responsiveness to $12 \mathrm{~L}: 12 \mathrm{D}$, but not in the timing of the response. In any case, this difficulty was avoided in Expt 2 since animals were preselected for a uniform response to the $12 \mathrm{~L}: 12 \mathrm{D}$ photoperiod. As in the first experiment, there was a significant involution when they were transferred to the shorter photoperiod.

An aspect of the photoperiodic requirements for termination of photorefractoriness is suggested by the group exposed to the sequence of $8 \mathrm{~L}: 16 \mathrm{D}, 12 \mathrm{~L}: 12 \mathrm{D}$ and finally $8 \mathrm{~L}: 16 \mathrm{D}$ photoperiods. Fourteen weeks of exposure to long days (for example, $14 \mathrm{~h}$ of light per $24 \mathrm{~h}$ ) is sufficient to terminate photorefractoriness (Stetson et al., 1977; Bittman, 1978), but herein we report that 12 L:12 D treatment was uniformly insufficient to restore sensitivity to a second exposure to short days. Thus, either the 12 L:12 D photoperiod is incapable of dissipating photorefractoriness or it requires a more prolonged exposure to do so than does a longer photoperiod.

The concentrations of circulating prolactin increased during the last 8 weeks of 12 L:12 D treatment. Previously, we had reported that serum concentrations of prolactin were continuously depressed during retention on $12 \mathrm{~L}: 12 \mathrm{D}$ for more than 40 weeks. The discrepancy is problematic, but one possibly significant difference between the previous results and those reported here is the age of the hamsters at the beginning of the experiment (adults in the previous experiments, prepubertal in the current report).

Prolactin concentrations decreased subsequent to transfer to either $8 \mathrm{~L}: 16 \mathrm{D}$ or even if retained on $12 \mathrm{~L}: 12 \mathrm{D}$. When retained on $12 \mathrm{~L}: 12 \mathrm{D}$, serum concentrations of prolactin rebounded again after another 20 weeks. These results are useful in the demonstration of the independence of prolactin secretion from the reproductive axis, despite the photoperiodic nature of both. The life expectancy of the hamster precludes our ability to determine whether or not a very prolonged exposure ( 2 years or more) would reveal a persistent rhythm of prolactin secretion. After involution and recrudescence, we have not observed spontaneous testicular regression with prolonged $12 \mathrm{~L}: 12 \mathrm{D}$ treatment for as long as one year. In any case, it seems likely that the $12 \mathrm{~L}: 12 \mathrm{D}$ photoperiod is a potentially useful tool in the study of the mechanisms of photoperiodic regulation of prolactin secretion as distinct from that of the gonadotrophins.

This work was supported by Research Grant DCB87-14638 from the National Science Foundation to M. H. Stetson. The authors thank T. Whelan for assistance with the animal care and K. M. Ogilvie for constructive comments.

\section{References}

Bittman EL (1978) Hamster refractoriness: the role of insensitivity of pineal target tissues Science $202648-650$

Blask DE, Leadem CA, Orstead KM and Larsen BR (1986) Prolactin cell activity in female and male Syrian hamsters: an apparent sexually dimorphic response to light deprivation and pinealectomy Neuroendocrinolozy 42 15-20

Darrow IM, Davis FC, Elliott JA, Stetson MH, Turek FW and Menaker M (1980) Influence of photoperiod on reproductive development in the golden hamster Biology of Reproduction 22 443-450

Donham RS, Palacio E and Stetson MH (1994) Dissociation of the reproductive and prolactin photoperiodic responses in male golden hamsters Biology of Reproduction 51 366-372

Follett BK and Pearce-Kelly A (1990) Photoperiodic control of the termination of reproduction in Japanese quail (Coturnix coturnix japonica) Proceedings of the Royal Society of London Series B 242 225-230

Gaston S and Menaker M (1967) Photoperiodic control of hamster testis Science 158 925-928

Goldman BD, Matt KS, Roychoudhury P and Stetson MH (1981) Prolactin release in golden hamsters: photoperiod and gonadal influences Biology of Reproduction 24 287-292

Hastings MH, Walker AP, Powers JB, Hutchinson J, Steel EA and Herbert J (1989) Differential effects of photoperiodic history on the responses of gonadotropins and prolactin to intermediate daylengths in the male Syrian hamster Journal of Biological Rhythms 4 335-350

Little JC, Vaughan MK, Haider N, Smith I and Reiter RJ (1986) Effects of afternoon injections of O-acetyl-5-methoxytryptophol, melatonin or 5-methoxytryptophol in female Syrian hamsters Journal of Neural Transmission $66291-301$

Malpaux B, Robinson JE, Brown MB and Karsch FJ (1988) Importance of changing photoperiod and melatonin secretory pattern in determining the length of the breeding season in the Suffolk ewe Journal of Reproduction and Fertility 83 46I-470

Matt KS and Stetson MH (1980) Comparison of serum hormone titers in golden hamsters during testicular growth induced by pinealectomy and photoperiodic stimulation Biology of Reproduction 23 893-898

Nicholls TJ, Goldsmith AR and Dawson A (1988) Photorefractoriness in birds and comparison with mammals Physiological Reviews 68 133-176

Reiter RJ (1981) The mammalian pineal gland: structure and function American Journal of Anatomy 162 287-313

Reiter RJ (1991) Pineal melatonin: cell biology of its synthesis and of its physiological interactions Endocrine Reviews 12 15I-180 
Reiter RJ, Sorrentino JS and Hoffman RA (1970) Early photoperiodic conditions and pineal antigonadal function in male hamsters International journal of Fertility 15 163-170

Robinson JE and Follett BK (1982) Photoperiodism in Japanese quail: the termination of seasonal breeding by photorefractoriness Proceedings of the Royal Society of London Series B $\mathbf{2 1 5} 95-116$

Rollag MD, DiPinto MN and Stetson MH (1982) Ontogeny of the gonadal response of golden hamsters to short photoperiod, blinding, and melatonin Biology of Reproduction 27 898-902

Rollag MD, Panke ES, Trakulrungsi W, Trakulrungsi C and Reiter RJ (1980) Quantification of daily melatonin synthesis in the hamster pineal gland Endocrinology 106 231-236

Sokal RR and Rohlf FJ (1981) Assumptions of analysis of variance Biometry: The Principles and Practice of Statistics in Biological Research pp. 400-453. W.H. Freeman and Co., New York

Steger RW and Bartke A (1991) Temporal sequence of neuroendocrine events associated with the transfer of male golden hamsters from a stimulatory to a nonstimulatory photoperiod Biology of Reproduction 44 76-82
Steger RW and Gay-Primel E (1990) Effects of melatonin injections on the ability of golden hamster pituitaries to secrete prolactin and luteinizing hormone Biology of Reproduction 42 217-221

Stetson MH, Watson-Whitmyre M and Matt KS (1977) Termination of photorefractoriness in golden hamsters - photoperiodic requirements Journal of Experimental Zoology 202 81-88

Vriend J and Wasserman RA (1986) Effects of afternoon injections of melatonin in hypothyroid male Syrian hamsters Neuroendocrinology 42 498-503

Watson-Whitmyre M and Stetson MH (1985) A mathematical method for estimating paired testes weight from in situ testicular measurements in three species of hamster Anatomical Record 213 473-476

Watson-Whitmyre M and Stetson MH (1988) Reproductive refractoriness in hamsters: environmental and endocrine etiologies. In Processing of Environmental Information in Vertebrates pp. 219-249 Ed. Springer-Verlag, New York

Wingfield JC (1993) Control of testicular cycles in the song sparrow, Melospiza melodia: interaction of photoperiod and an endogenous program? General and Comparative Endocrinology 92 388-401 